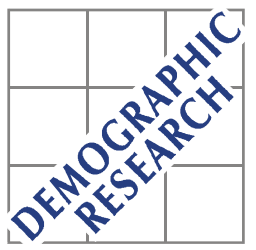

Demographic Research a free, expedited, online journal of peer-reviewed research and commentary in the population sciences published by the Max Planck Institute for Demographic Research Konrad-Zuse Str. 1, D-18057 Rostock · GERMANY www.demographic-research.org

DEMOGRAPHIC RESEARCH

VOLUME 13, ARTICLE 16, PAGES 389-414

PUBLISHED 17 NOVEMBER 2005

http://www.demographic-research.org/Volumes/Vol13/16/

DOI: $10.4054 /$ DemRes.2005.13.16

Research Article

Estimates of mortality and population changes in England and Wales over the two World Wars

Dmitri Jdanov

Evgeny Andreev

Domantas Jasilionis

Vladimir M. Shkolnikov

This article is part of Demographic Research Special Collection 4, "Human Mortality over Age, Time, Sex, and Place: The $1^{\text {st }}$ HMD Symposium".

Please see Volume 13, publications 13-10 through 13-20.

(C) 2005 Max-Planck-Gesellschaft. 


\section{Table of Contents}

$1 \quad$ Introduction $\quad 390$

$2 \quad$ Data and Methods 392

$2.1 \quad$ The First World War (1914-1918) 392

$2.2 \quad$ The Second World War (1939-1945) 394

2.3 Methods 396

$3 \quad$ Model 397

$\begin{array}{lll}3.1 & \text { Population flows } & 397\end{array}$

$\begin{array}{lll}3.2 & \text { Assumptions } & 399\end{array}$

3.3 Parameterized model 400

3.4 The minimization functional 402

$4 \quad$ Results 404

4.1 The First World War 405

4.2 The Second World War 408

$\begin{array}{lll}5 & \text { Conclusion } & 409\end{array}$

6 Acknowledgements 411

$\begin{array}{ll}\text { References } & 412\end{array}$ 


\title{
Estimates of mortality and population changes in England and Wales over the two World Wars
}

\author{
Dmitri Jdanov ${ }^{1}$, \\ Evgeny Andreev ${ }^{2}$, \\ Domantas Jasilionis ${ }^{1}$, \\ Vladimir M. Shkolnikov ${ }^{1}$
}

\begin{abstract}
Almost one million soldiers from England and Wales died during the First and Second World War whilst serving in the British Armed Forces. Although many articles and books have been published that commemorate the military efforts of the British Armed Forces, data on the demographic aspects of British army losses remain fragmentary. Official population statistics on England and Wales have provided continuous series on the civilian population, including mortality and fertility over the two war periods. The combatant population and combatant mortality have not been incorporated in the official statistics, which shows large out-migration at the beginning and large in-migration towards the end of the war periods. In order to estimate the dynamics of the total population and its excess mortality, we introduce in this paper a model of population flows and mortality in times of war operations. The model can be applied to a detailed reconstruction of war losses, using various shapes of the input data. This enables us to arrive at detailed estimates of war-related losses in England and Wales during the two world wars. Our results agree with elements of data provided by prior studies.
\end{abstract}

This article is part of Demographic Research Special Collection 4, "Human Mortality over Age, Time, Sex, and Place: The $1^{\text {st }}$ HMD Symposium". Please see Volume 13, Publications 13-10 through 13-20.

\footnotetext{
${ }^{1}$ Max Planck Institute for Demographic Research, Rostock, Germany

${ }^{2}$ Centre of Demography and Human Ecology, Moscow, Russia
} 
Jdanov et al.: Estimates of mortality and population changes in England and Wales

\section{Introduction}

Reliable statistics covering the whole population of England and Wales date back to the beginning of the 19th century. Only a few countries in the world have longer continuous data series on their population. The historical data on England and Wales have a number of unresolved problems, however. In this paper, we address one of them: the incompleteness of population figures for the periods covering the two world wars.

Data on the British population for these periods are split into two separate series. As to the war times, the statistical office collected information on the civilian population only. Data on the combatant population fell under the responsibility of the country's military agencies. The two data series differ in their completeness and quality, however. Information on the civilian population is complete and reliable by large. War-time data on the non-civilian population are fragmentary with the result that continuous demographic data on the total population of England and Wales and covering the two world wars are incomplete.

The importance of including military data is demonstrated by a comparison between adjusted mortality data for France and corresponding unadjusted official data for England and Wales (Figure 1). The military population of France has been included in the calculations of the mortality surface, and this has led to significant peaks in mortality during both wars (Vallin, 1973). The corresponding unadjusted official figures for the total population of England and Wales show only small mortality increases. These increases are not only due to the direct and indirect effects of both wars (e.g., air strikes or food shortages), but possibly also the result of including the official death statistics of wounded combatants in English hospitals.

After having reviewed selected published sources, we arrive at several conclusions. First, it seems that historians and historical demographers have been attracted to British population losses in the First World War much more so than to loss in the Second World War. Second, complete official demographic data on the civilian population are available, but data on the combatant population are missing, questionable, or very approximate only (Winter, 2003). Most of the official data on combatants (coming from vital statistics or military reports) must be evaluated critically as they are affected by different types of errors (Winter, 1977, 2003).

So far, only a few attempts have been completed to reconstruct total population figures for England and Wales during the First and Second World War. Suffice it to mention the works of J.M. Winter, which are probably the best known. His estimates are based on mortality rates drawn from life tables of the Prudential Life Insurance Company (Winter, 1976, 2003).

Officially published data on the British Armed Forces (CSO, 1995) covering the First World War seem to be more detailed than equivalent data collections on the Second World 
Figure 1: Life expectancy at birth and probability of death at age 25 for France (total population), England and Wales (civilian population only), males (blue line with stars) and females (red)
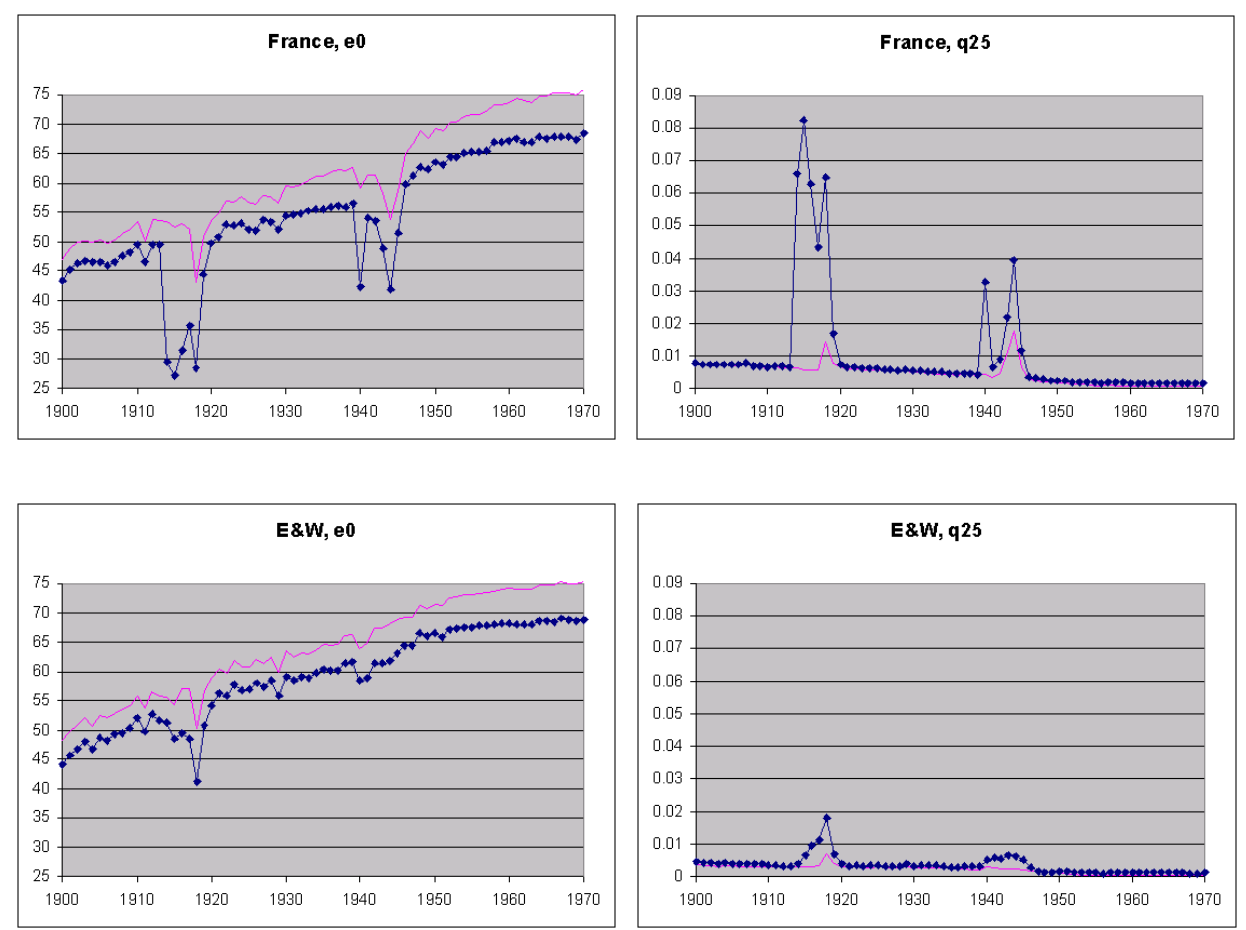

Note an increase of mortality in 1918 due to the influenza epidemic. Data stem from the Human Mortality Database (http://www.mortality.org) 
Jdanov et al.: Estimates of mortality and population changes in England and Wales

War. However, they do not allow for an estimation of combatant mortality - as does the data on the First World War. Unfortunately, only approximate and aggregate data on combatant deaths from England and Wales have been published, covering each year of WWII (see Urlanis, 1971). There are virtually no published data on military losses by age, except for mortality indicators by selected diseases and services of the British Armed Forces (Ellis, 1972; Mayne, 1972; Welch, 1972; Brooke, 1972). However, additional data on the British Armed Forces (e.g., age distribution or net change in army strength) provide us with precise guidelines for estimating the age-specific mortality of combatants during the Second World War.

Our study aims at filling the gap in the data on England and Wales by reconstructing a complete mortality surface that includes the combatant population for the First and Second World War. Taking into consideration the varying availability and quality of the input data, we intend to produce comparable estimates for both wars. Moreover, the proposed method, which is based on a model of population flows, can be used to reestimate mortality surfaces in similar situations where the demographic data available is fragmentary.

\section{Data and methods}

We use data on the civilian population provided by the Human Mortality Database (HMD, http://www.mortality.org). The HMD contains detailed information on mortality and population, based on official data from the Central Statistical Office (CSO). As mentioned above official statistics on the combatant population are fragmentary and stem from different sources (military authorities, CSO and Registrar General). Below, we provide a short overview of the data available.

\subsection{The First World War (1914-1918)}

J.M. Winter (1976, 2003) gives a comprehensive overview of the official statistics available on British military losses during the First World War. The author argues that neither census/vital statistics nor military reports provide precise figures on population loss in times of war operation (Winter, 1976). Information on the combatant population seems to be affected most.

The General Annual Report of the British Army 1913-1919 (Army Council, 1921), Statistics of Military Effort of the British Empire during the Great War (The War Office, 1922), and Casualties and Medical Statistics of the Great War (Mitchell and Smith, 1931, 1997) are the most widely used official military data sources on British casualties during the First World War (see Urlanis, 1971, and Winter, 1976, 2003 for more details). Reports published by military authorities (including those mentioned above) are incomplete and 
provide only approximate data (Winter, 1976, 2003). To our knowledge, detailed data on military loss, such as on the age structure of the dead, have not been collected or published. Army officials acknowledged serious shortcomings of military statistics. Surgeon Vice-Admiral Sheldon F. Dudley (1942) and Ellis (1972), for example, pointed out that vital statistics on the Navy were compiled up to the end of 1915 only. Another area of concern is the registration of military casualties immediately or even several years after the end of war. In some reports, casualties owing to the British intervention in Russia or from wounded or disabled soldiers were counted as deaths resulting from war operations, although they occurred when the war was over (after 11 November 1918) (Winter, 2003).

Estimations of British war losses vary significantly, depending on the data source used. According to J.M. Winter (2003), figures range from 550,000 to 1,184,000 casualties. Most of the authors providing such estimates have relied solely on official data; only few attempts have been made to employ alternative data sources and methods. Typically, total war loss has been calculated by comparing "hypothetical" population trends (under no-war conditions) and actual population figures, with the resulting figures usually having been attributed to war casualties (Urlanis, 1971).

Winter $(1976,2003)$ has estimated the age structure of English WWI losses using alternative data sources (namely, life tables of the Prudential Life Insurance Company). These life tables cover information on five million men of working age; about $30 \%$ of them served in the British Armed Forces during the war (Winter, 2003). The author first calculated the total population estimates for 1912-1918 by multiplying the 1911 census population by the survivor ratios provided by Prudential life tables for 1913-1918. The total number of deaths was derived by applying age-specific death rates from Prudential to the corresponding population estimates. Second, a hypothetical population size in times of peace (as if there had been no war) was estimated for 1914-1918 by applying average annual rates of mortality decrease for the 1901-1912 period to the 1911 census population (under the assumption that further mortality decline is linear). A hypothetical number of deaths "without the effect of war" was derived by using an identical procedure as to the total number of deaths. Finally, he obtained war-related deaths from the difference between the total number of deaths and the deaths "without the effect of war". Although the Prudential data have certain limitations, Winter has produced the most reliable estimate of WWI losses so far.

The following data are available for WWI:

- The total number of the British combatant population for each year of the war (Table 1). The British Armed Forces then consisted of conscripts from England and Wales to the tune of $86 \%$ (Winter, 1977).

- The total number of British military casualties during WWI and indirect estimations of the number killed each year of the war for England and Wales (Table 1).

- Age-specific war-related deaths for every year of the 1914-1917 period and derived 
Jdanov et al.: Estimates of mortality and population changes in England and Wales

from Prudential life tables (Winter, 2003). These data, which are based on a population sample, can be used for the verification of results only.

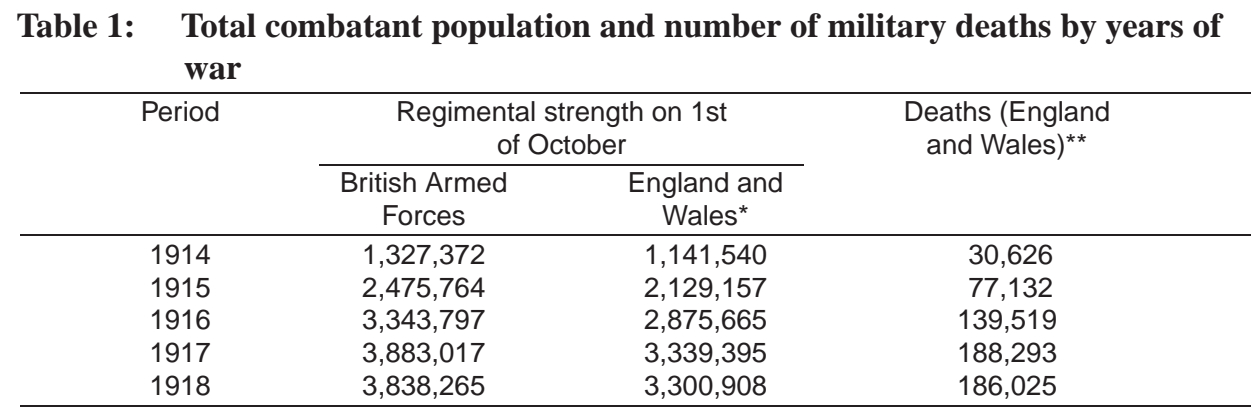

* 86 percent of the regimental strength of the British Armed Forces

** 86 percent of the total military deaths for Great Britain and Ireland, according to the Prudential estimates of war losses and the General Annual Report of the British Army 1913-1919. Military deaths for each calendar year were estimated by applying the corresponding proportions of annual war-related deaths drawn from Winter (2003) to the total number of military deaths for the whole period of war published by the Army Council (1921).

Sources: The Army Council (1921); General Annual Report of the British Army 1913-1919. Cmd 1193; Winter, J.M. (2003). The Great War and the British People. Palgrave Macmillan, 360 p.

\subsection{The Second World War (1939-1945)}

Published official data on the strength of the British Armed Forces are more detailed for the Second World War than for the First World War. Published as a series on the History of the Second World War (United Kingdom Medical Series), Casualties and Medical Statistics (1972) presents the most detailed data on the number of war deaths in the British Armed Forces and their distribution by age and cause. However, total combatant mortality cannot be constructed from this rich statistical source as the information contained therein relates to different branches of the Forces or to hospitals even. It is therefore impossible to aggregate this data to represent mortality indicators that are relevant to the total combatant population.

"A Statistical Digest of the Second World War" published by the Central Statistical Office $(1951,1995)$ is another example of attempts to provide detailed data on the combatant population of Great Britain. Although the publication provides readers with information on the strength of the Armed Forces by age and year of war, its death statistics are difficult to use when it comes to demographic analysis. Most of the data on British military losses come under the broad term of "casualties", which includes the injured, prisoners of war, and missing combatants etc.; thus not allowing for a distinction to be 
made between deaths and other casualties (e.g., wounded prisoners of war). It seems that these problems have distorted corresponding figures published on the strength of the British Armed Forces. Comparing the Statistical Digest figures on the non-civilian population of England and Wales with those of Registrar General (1951), it appears that in some age groups this population exceeds the total British combatant population. Another work, "Statistical Review of England and Wales for the Six Years 1940-1945", published by Registrar General (1951) provides data on total and civilian population estimates for England and Wales. It relies not only on information from routine statistics and records of the Service Departments of the British Armed Forces but also on additional data, such as the records obtained from food ration books. As a result, Registrar General has been able to produce higher quality data on the total population, civilian as well as non-civilian (calculated by subtracting the total by the civilian figures) for the war years.

The examples above illustrate that published statistics on combatant mortality during the Second World War have major problems. Incompleteness of military statistics has been attributed elsewhere to the specifics of war conditions and poor administration (Mayne, 1972). Suffice it to mention two examples: First, the quarterly journals of medical officers were the only data source available to compile death statistics on the Naval Forces (Ellis, 1972). As a ship was lost, so were the medical journals and thus the number of resulting deaths, making for incomplete annual reports on the Navy (Ellis, 1972). Second, information on the fate (i.e., dead or alive) of missing military personnel and prisoners of war often became available only several years following the war, thus limiting war-time data collection on annual military deaths. As a result, only approximate and aggregate data on combatant deaths in the British Armed Forces by each year of war have been published (Urlanis, 1971). Military statistics were also affected by secrecy and several administrative reforms that took place during the war (Ellis, 1972). In this respect, Great Britain lagged behind the USA, where the registration of casualties seems to have been more accurate, and considerably better quality (for example, see "Statistical Review. World War II" published by the Army Service Forces in 1956).

The following data are available for WWII:

- Official estimates for the non-civilian population of England and Wales by five year age groups, 1940-1945 (Table 2).

- The number of military deaths in the Armed Forces of England and Wales for each year of the war, 1939-1945 (Table 3).

- The demobilization of the British forces in 1945, 1946, and 1947: 1,342,107, 2,545,215, and 591,648 people, respectively (CSO, 1995). 
Jdanov et al.: Estimates of mortality and population changes in England and Wales

Table 2: Mid-year population estimates (in thousand) for the non-civilian population of England \& Wales by five-year age groups, 1940-1945

\begin{tabular}{crrrrrr}
\hline Age $\backslash$ Year & 1940 & 1941 & 1942 & 1943 & 1944 & 1945 \\
\hline $0-14$ & 0 & 0 & 0 & 0 & 0 & 0 \\
$15-19$ & 149 & 207 & 242 & 358 & 364 & 351 \\
$20-24$ & 845 & 1,056 & 1,110 & 1,225 & 1,230 & 1,155 \\
$25-29$ & 455 & 812 & 854 & 944 & 976 & 1,001 \\
$30-34$ & 236 & 491 & 617 & 760 & 821 & 846 \\
$35-39$ & 139 & 216 & 345 & 467 & 529 & 579 \\
$40-44$ & 77 & 82 & 143 & 201 & 240 & 296 \\
$45-49$ & 47 & 37 & 43 & 62 & 72 & 70 \\
$50-54$ & 21 & 10 & 21 & 34 & 37 & 36 \\
$55-59$ & 4 & 2 & 3 & 8 & 12 & 11 \\
$60-64$ & 0 & 0 & 0 & 3 & 3 & 3 \\
$65-69$ & 0 & 0 & 0 & 1 & 1 & 1 \\
$70+$ & 0 & 0 & 0 & 0 & 0 & 0 \\
TOT & 1,973 & 2,913 & 3,378 & 4,063 & 4,285 & 4,349 \\
\hline
\end{tabular}

Source: Registrar General (1951). Statistical Review of England and Wales for the Six Years 1940-1945. Vol.II. HMSO, London, p.10.

Table 3: Military losses of England and Wales by year, WWII

\begin{tabular}{|c|c|c|c|c|c|c|c|}
\hline Year & 1939 & 1940 & 1941 & 1942 & 1943 & 1944 & 1945 \\
\hline Killed* & 880 & 18,952 & 15,197 & 34,768 & 48,584 & 55,972 & 69,153 \\
\hline
\end{tabular}

${ }^{*}$ Calculated according to the proportion of soldiers from England and Wales in the British Military Forces, 1939-1945.

Sources: Urlanis, B. (1971). Wars and Population. Progress Publishers, Moscow, 320 p. and Registrar General (1951). Statistical Review of England and Wales for the Six Years 1940-1945. Vol.II. HMSO, London, p.10.

\subsection{Methods}

Our methodology for the reconstruction of the total population figures is based on a modeling approach. We propose an extended model of population flows that allows for the reconstruction of age-specific mortality surfaces using diverse input data. The model does not assume an a priori choice of its parameters. It finds the parameters in a zone of possible solutions by solving an optimization problem. In addition to suggesting a rather simple way of estimating unknown demographic data in the balancing equation of population, this approach also allows for an analysis of possible alternatives with optimally balanced requirements. The model is flexible and can easily be revised and extended depending on the availability and features of the input data (but still producing comparable 
results). The latter properties are particularly important for obtaining consistent estimates across different time periods (e.g. WWI and WWII) or for various countries.

We apply the parameterized model to estimate the dynamics of the whole population and excess mortality in England and Wales during WWI and II. As an outcome we get optimal (in defined terms) mortality and population estimates. This approach has the advantage of a rapid analysis of possible alternatives with optimally balanced requirements as well as flexibility with respect to various modifications.

\section{Model}

The balancing equation of population change is taken as a starting point and population is defined as referring to one-year cohort data (Section 3.1). Thus, all unknown elements of the data (deaths by one-year age group, migration, etc.) can be interpreted as variables. To simplify the model, we introduce a set of hypotheses in Section 3.2 that allow us to reduce the number of parameters (see Section 3.3.). We need to define a criterion in order to choose an optimal solution (an optimal set of parameters). We use the minimization of functional (Section 3.4) as such a criterion.

\subsection{Population flows}

We propose a model based on the following population flows: As input stream for the civilian population we consider in-migration and demobilization, and the corresponding output stream includes out-migration, (civilian) deaths, and mobilization (see the flowchart in Figure 2). As to the combatant population, mobilization is the only input stream, whereas the output one includes (military) deaths and demobilization. Now that the streams are defined, our main goal is to determine all parts of input/output streams.

The equations can be formulated as follows. Let $P^{c}(t, y)$ be the number of persons alive at time $t$ (on January 1 st of year $t$ ) in cohort $y, D^{c}(t, y)$ is the number of civilian deaths in year $t$ and cohort $y, M(t, y)$ is the net-migration between time $t$ and $t+1$ to cohort $y$. As to war time, the balance of change in the civilian population also includes the components described by mobilization: the number of conscripts $C o n(t, y)$, mobilized from cohort $y$ in year $t$, and the number of dischargees $\operatorname{Dis}(t, y)$, demobilized in year $t$. Thus, for the civilian population we have the following equation ${ }^{3}$ :

$$
P^{c}(t+1, y)=P^{c}(t, y)-D^{c}(t, y)-\operatorname{Con}(t, y)+\operatorname{Dis}(t, y), t>y
$$

The equation for the military population can be written as

$$
P^{m}(t+1, y)=P^{m}(t, y)-D^{m}(t, y)+\operatorname{Con}(t, y)-\operatorname{Dis}(t, y), t>y
$$

\footnotetext{
${ }^{3}$ We do not include the part for the newborn cohort because it does not affect any of the calculations below.
} 
Jdanov et al.: Estimates of mortality and population changes in England and Wales

Figure 2: Model of population flows and mortality in war operations

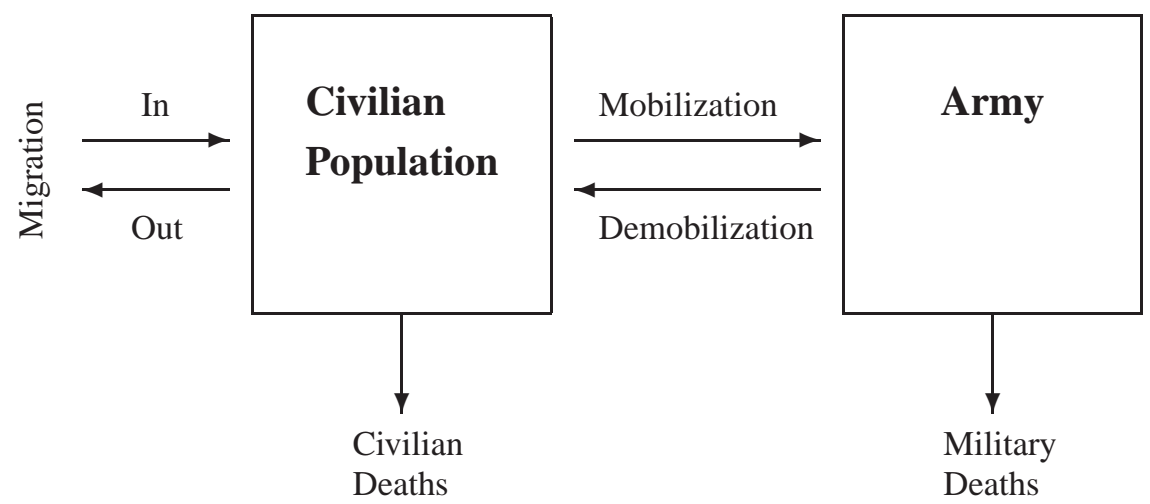

where $P^{m}$ and $D^{m}$ denote the military population (or members of the Armed Forces) and military deaths, respectively. When data for some of the components are available by aggregate age group only, if they are available at all, they can be reconstructed from these equations. Unfortunately, these equations would then have more than one solution. In other words, we need to choose one trajectory from a set of trajectories satisfying equations (1) and (2). As a possible selection criterion we could use the maximum likelihood principle. However, then we would have to solve several problems. First, the large number of unknown variables would have to be reduced. For example, given that the period of war is five years and all data except military deaths are known, we would need to apply a system of equations with 135 unknown variables ${ }^{4}$ in order to reconstruct the age structure of war related deaths. Second, we need to take into account that other demographic data (e.g., on migration) are hardly available or if they are, they are of questionable quality. Therefore, we are proposing the following assumptions that will solve the aforementioned problems.

\footnotetext{
${ }^{4}$ We assume that the "military" ages cover ages 18-45.
} 


\subsection{Assumptions}

a) The baseline probability of deaths is the same for both the non-civilian (members of the Armed Forces) and civilian populations ${ }^{5}$. An excess of mortality due to war can be described by a gamma p.d.f. likely function with a maximum around age 18-20 (see examples of France (Vallin, 1973) or the Prudential life tables in Winter (1976)). Therefore, we use the sum of two probability density functions of the gamma distribution ${ }^{6} G_{1}\left(x ; b_{1}, b_{2}\right)$ and $G_{2}\left(x ; b_{3}, b_{4}\right)$. The second function is introduced for a(n) (possible) additional peak at higher ages, i.e. 20-25 years. This peak may occur during Navy and Air Force operations resulting in a relative high number of casualties among the soldiers and officers more trained than others. Thus, the probability of death $q^{m}(t, y)$ for military cohort $y$ in year $t$ can be defined via the civilian probability of death as follows:

$$
\begin{aligned}
q^{m}(t, y)= & q^{c}(t, y)+b_{0}(t) *\left(G_{1}\left(t-y ; b_{1}(t), b_{2}(t)\right)+\right. \\
& \left.+G_{2}\left(t-y ; b_{3}(t), b_{4}(t)\right)\right),
\end{aligned}
$$

where $b_{0}(t)$ determines the relative levels of mortality by year, and $b_{1}(t)$ to $b_{4}(t)$ determine the shape of mortality distribution by age for every year.

b) Unknown migration should be minimized. It means that of all possible solutions of the balancing equation that satisfy the known data and conditions, the most likely solution is the one with minimal net migration. This allows us to define a number of conscripts and net migration even without knowing the strength of the Armed Forces.

c) Migration, mobilization, and demobilization are distributed uniformly within the elementary time intervals, i.e. the year or part of the year for mobilization/demobilization in the first/last year of war.

d) The process of mobilization stops with the end of the war. Soon after, for example before the first after-war census took place, all mobilized persons should be demobilized.

e) Initial populations at the start and the end points of the period considered in the model should agree with each other. Both of them should either include civilians

\footnotetext{
${ }^{5}$ Unfortunately, we are not able to consider any likely health selection effects as the Armed Forces tend to recruit relatively healthy persons. Unhealthy persons, consequently unfit for military service, tends to be confined to the civilian population. This may have produced a slightly elevated mortality risk among the civilian population. Thus, taking the assumption of equal baseline probabilities of dying, we may have slightly over-estimated the mortality gap between the combat and civilian populations. Nevertheless, this effect will be negligible compared to mortality excess resulting from to war operations.

${ }^{6}$ The gamma probability density function $G(x ; a, b)$ with parameters $a$ and $b$ is defined for each age $x$ as $G(x ; a, b)=\frac{1}{b^{a} \Gamma(a)} x^{a-1} e^{\frac{x}{b}}$, where $\Gamma(a)$ is a standard gamma function.
} 
Jdanov et al.: Estimates of mortality and population changes in England and Wales

only or civilians and combatants. This is the case for England and Wales: since populations counted by the last pre-war census and the first after-war census include booth civilian and military parts.

\subsection{Parameterized model}

Taking into consideration the assumptions above, we modify the initial model (1)-(2). Let $t_{\text {begin }}$ be the first calendar year of war, $t_{\text {end }}$ denote the last year of war, and $T$ represent the (first) year by which all additional troops have been demobilized. We assume that before year $t_{\text {begin }}$, the total population is equivalent to the civilian population; in all other cases, $t_{\text {begin }}$ can be defined as the first year of mobilization. For WWI, $t_{\text {begin }}=1914$, $t_{\text {end }}=1918$, and $T=1921$ (the year of the first post war census). Similarly, as to Second World War, $t_{\text {begin }}=1939, t_{\text {end }}=1945$, and $T=1951$.

Suppose that the war began and ended on January 1st. Taking into account assumption (c), formula (1) for the "military" cohort can be written in the form of

$$
\begin{aligned}
P^{c}(t+1, y)= & P^{c}(t, y) *\left(1-q^{c}(t, y)\right)+M(t, y), t<t_{\text {begin }}, \\
P^{c}(t+1, y)= & P^{c}(t, y) *\left(1-q^{c}(t, y)\right)-\operatorname{Con}(t, y) *\left(1+\frac{1}{2} q^{c}(t, y)\right)+ \\
& + \text { Dis }(t, y) *\left(1-\frac{1}{2} q^{c}(t, y)\right)+M(t, y), t_{\text {begin }} \leq t<t_{\text {end }}, \\
P^{c}(t+1, y)= & P^{c}(t, y) *\left(1-q^{c}(t, y)\right)+ \\
& +\operatorname{Dis}(t, y) *\left(1-\frac{1}{2} q^{c}(t, y)\right)+M(t, y), t_{\text {end }} \leq t<T
\end{aligned}
$$

In other words, we can calculate the number of conscripts for $t_{\text {begin }} \leq t<t_{\text {end }}$ as

$$
\begin{aligned}
\operatorname{Con}(t, y)= & \frac{P^{c}(t, y) *\left(1-q^{c}(t, y)\right)-P^{c}(t+1, y)}{1+\frac{1}{2} q^{c}(x, t)}+ \\
& +\frac{D i s(t, y) *\left(1-\frac{1}{2} q^{c}(t, y)\right)+M(t, y)}{1+\frac{1}{2} q^{c}(x, t)}
\end{aligned}
$$

and the number of discharges for $t_{\text {end }} \leq t<T$ as

$$
\operatorname{Dis}(t, y)=\frac{P^{c}(t+1, y)-P^{c}(t, y) *\left(1-q^{c}(t, y)\right)-M(t, y)}{1-\frac{1}{2} q^{c}(x, t)}
$$

Here we assume that no conscription took place after the end of war. Similarly to equation (5), we obtain from (2) that 


$$
\begin{aligned}
P^{m}(t+1, y)= & P^{m}(t, y) *\left(1-q^{m}(t, y)\right)+\operatorname{Con}(t, y) *\left(1-\frac{1}{2} q^{m}(t, y)\right)- \\
& -\operatorname{Dist}(t, y) *\left(1+\frac{1}{2} q^{m}(t, y)\right),
\end{aligned}
$$

for $t_{\text {begin }} \leq t<t_{\text {end }}$. For $t_{\text {end }} \leq t<T$, the equation (7) is replaced by (8)

$$
P^{m}(t+1, y)=P^{m}(t, y) *\left(1-q^{m}(t, y)\right)-\operatorname{Dis}(t, y) *\left(1-\frac{1}{2} q^{m}(t, y)\right)
$$

with $\operatorname{Dis}(t, y)$ from (6).

Above, we have assumed that data on migration are known. Unfortunately, the latter is a theoretical rather than a practical case. Data on net migration for England and Wales are available only for some years and merely by aggregate age groups. Furthermore, even these limited data seem to be hardly acceptable to our purposes due to their insufficient quality. During both war conditions, it was extremely difficult to follow inward and outward flows to and from the Armed Forces as many records of dischargees (e.g., due to injury) from the army were lost on the battlefields (Ellis, 1972). Some wounded soldiers possibly were included in the civilian population count without having entered them into official records of discharge from the army. These persons therefore have been counted twice, i.e., as "civilian" and as "soldier".

Nevertheless, equation (5) can be adjusted according to data availability on different components. Net migration can be approximated by the parameterized function. In order to simplify the equation, we use the gamma probability density function $G_{3}\left(x ; k_{1}, k_{2}\right)$ for the further modeling of migration:

$$
M(t, y)=k_{0}(t) * G_{3}\left(t-y ; k_{1}(t), k_{2}(t)\right),
$$

where $k_{0}(t)$ determines the level of migration in year $t$, and $k_{1}(t)$ and $k_{2}(t)$ determine the shape of the migration curve in each year.

Taking into account the unknown official numbers of conscripts and dischargees during the war and treating conscription and discharge as analogous to migration, we can replace the respective flows of mobilization/demobilization by "net conscription". The latter will be equivalent to the reduced flow of mobilization. Thus, our model will be similar to the one without demobilization during war times, with an unknown number of conscripts. The model (5)-(8) thus will be equivalent to the simplified model below: During the war for years $t \geq t_{\text {begin }}$, the unknown components can be defined as 
Jdanov et al.: Estimates of mortality and population changes in England and Wales

$$
\begin{gathered}
C o n(t, y)=\frac{P^{c}(t, y) *\left(1-q^{c}(t, y)\right)-P^{c}(t+1, y)+M(t, y)}{1+\frac{1}{2} q^{c}(t, y)}, \\
P^{m}(t+1, y)=P^{m}(t, y) *\left(1-q^{m}(t, y)\right)+\operatorname{Con}(t, y) *\left(1-\frac{1}{2} q^{m}(t, y)\right),
\end{gathered}
$$

For $t_{\text {end }} \leq t<T$, equation (11) is replaced by (8) with Dis $(t, y)$ from (6). Taking into account our assumption about $t_{\text {begin }}$ and $T$, we can define the first and last points in the model:

$$
\begin{aligned}
& P^{m}\left(t_{\text {begin }}, y\right)=P^{m}(T, y)=0, \\
& P^{c}\left(t_{\text {begin }}, y\right)=P\left(t_{\text {begin }}, y\right), \\
& P^{c}(T, y)=P(T, y) .
\end{aligned}
$$

If we reject the assumption that the wars began and ended on January 1st, the number of conscripts is calculated as

$$
\operatorname{Con}(t, y)=\frac{P^{c}(t, y) *\left(1-q^{c}(t, y)\right)-P^{c}(t+1, y)+M(t, y)}{1+\frac{1}{2} \tau_{t} q^{c}(x, t)}
$$

where $\tau_{t}$ is the war part of year $t$. Correspondingly, the equation for demobilization is

$$
\operatorname{Dis}(t, y)=\frac{P^{c}(t+1, y)-P^{c}(t, y) *\left(1-q^{c}(t, y)\right)-M(t, y)}{1-\frac{1}{2}\left(1-\tau_{t}\right) * q^{c}(x, t)},
$$

\subsection{The minimization functional}

To finalize our model, we need to define a minimization functional. The type of functional depends on the data available. For WWI, it can be written as 


$$
\begin{aligned}
& \quad \lambda_{1} \sum_{t_{\text {begin }}<t<t_{\text {end }}}\left(\mathbf{D}^{m}(t)^{-1}\left(\sum_{y} D^{m}(t, y)-\mathbf{D}^{a}(t)\right)\right)^{2}+ \\
& +\quad \lambda_{2} \sum_{t_{\text {begin }}<t<t_{\text {end }}}\left(\mathbf{P}^{m}(t)^{-1}\left(\sum_{y} P^{m}(t, y)-\mathbf{P}^{m}(t)\right)\right)^{2}+ \\
& +\quad \lambda_{3} \sum_{t_{\text {begin }}<t<T}\left(\sum_{y} P^{c}(t, y)^{2}\right)^{-1} \sum_{y} M(t, y)^{2}+ \\
& +\quad \lambda_{4} \sum_{t_{\text {end }}<t<T} \mathbf{P}^{a}\left(t_{\text {begin }}+1\right)^{-2} \sum_{y}\left(t-t_{\text {end }}\right) P^{m}(t, y)^{2} \rightarrow \min _{b_{0}, \ldots, b_{n}, k_{0}, \ldots, k_{m}}
\end{aligned} .
$$

Here, $\mathbf{D}^{a}(t)$ denotes the total number of military deaths in year $t, \mathbf{P}^{a}(t)$ is the strength of the army in year $t$. The terms define the discrepancy between the estimated number of deaths and the total number of deaths known, the discrepancy in population estimates, migration, and army strength after the war, respectively. Coefficients $\lambda_{1}, \ldots, \lambda_{4}$ determine the relative weight of terms and depend on the quality and importance of the different parts of available data. Their values determine the relative importance of decrease in the respective term. For example, an increase in $\lambda_{1}$ promotes a decrease in the difference between the estimated number of deaths and the known total number of deaths. It is clear that the differences between official and simulated data have a greater importance than the level of migration and army strength after the war. Moreover, as death statistics usually are more reliable, we should take $\lambda_{1} \gg \lambda_{i}, i=2,3,4$. We have tested different ratios of $\lambda_{i}, i=1, \ldots, 4$ and selected the set of coefficients which produces the closest and most reliable result compared to the outcomes of other studies. As to the minimization functional (15) for WWI, we apply the following coefficients: $\lambda_{1}=10, \lambda_{2}=5, \lambda_{3}=1$, and $\lambda_{4}=0.1$. Figure 3 shows the sensitivity of the fit of combatant deaths and the strength of the army to changes in lambdas. Four panels of Figure 3 correspond to one-dimensional variations in each $\lambda_{i}, i=1, \ldots, 4$ by holding the values of the other lambdas constant. As one can see, for each lambda there is an interval of acceptable values with minimal differences between estimations and official data. Within these intervals, the resulting fits are almost independent of the exact values of the lambdas. It means that the proposed model is stable in respect to parameters $\lambda_{i}, i=1, \ldots, 4$ and that small changes in $\lambda_{i}$ have only a negligible impact on mortality estimates. More precise and reliable data are available for WWII, and this invites us to employ another value of coefficient $\lambda_{2}$. We take $\lambda_{2}=8$ to increase the weight of the population estimation in the functional to be minimized.

Thus, the input arguments of the model are: civilian population and deaths by one 
Jdanov et al.: Estimates of mortality and population changes in England and Wales

year age groups, army strength for years of war $\mathbf{P}^{m}(t)$, and distributions of total military deaths by years of war $\mathbf{D}^{m}(t)$. We have nine parameters for each year of war (see equations (3), (9)-(11)) and three parameters for each postwar year (see (8) and (9)). To choose these variables, we need to minimize the functional (15). As output, we get the combatant population and military deaths by one-year age group for each calendar year before the first after-war census.

Figure 3: Dependence of the fit of total combatant deaths (1914-1918) and army strength (1914-1917) on changes of $\lambda_{i}, i=1, \ldots, 4$
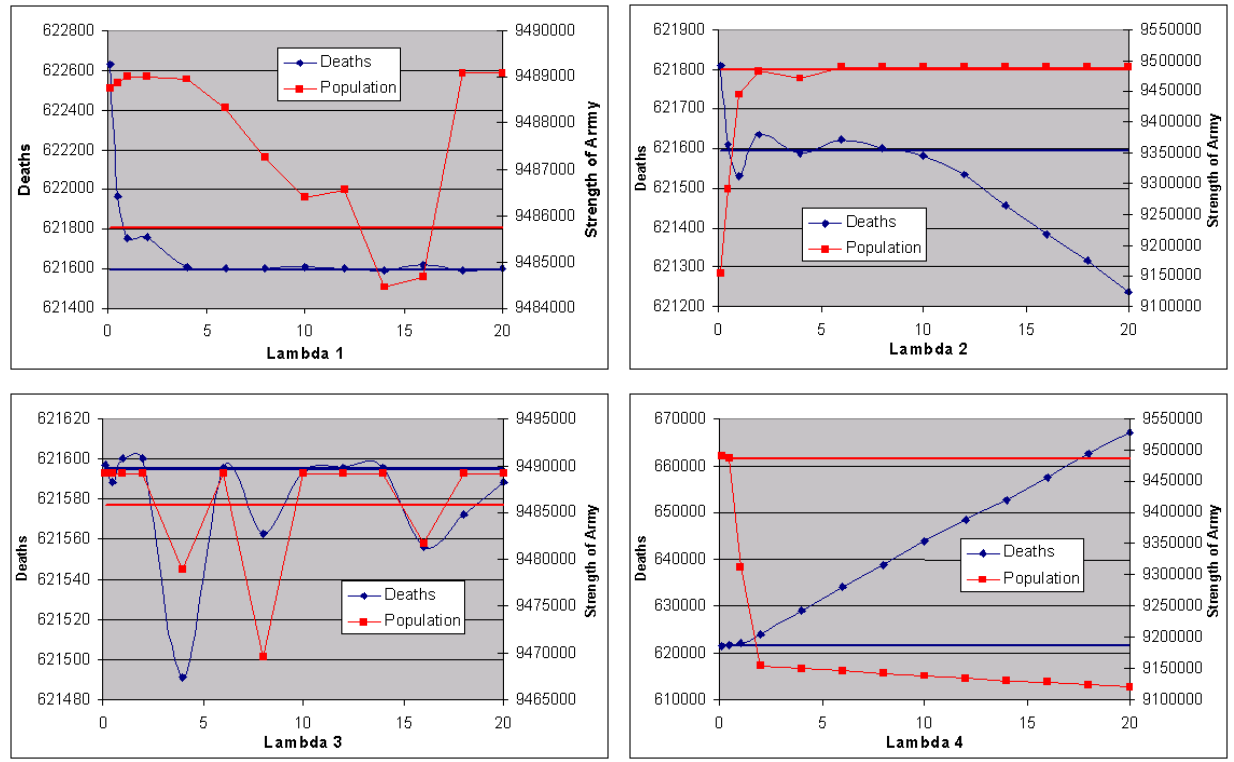

\section{Results}

In order to estimate the dynamics of the total population of England and Wales and excess mortality in WWI and WWII, we apply parameterized model of population flows and mortality in war operations. The same model fits to the data separately for each period of war. As a result, we obtaine new series of mortality indicators for both the combatant and adjusted total population of England and Wales, thereby accounting for mortality among the military population. 


\subsection{The First World War}

We apply the following assumptions related to net migration during the First World War. Net migration is zero during the war years. Model 1 includes post-war net migration only. As an alternative we consider a model with migration during the war (Model 2). Both models produce reasonable results, which are concordant with other data sources (Table 4).

Table 4: Results of a simulation for WWI. Model 1 has zero migration during the war. Model 2 is the same model but includes migration in times of war

\begin{tabular}{|c|c|c|c|c|c|}
\hline \multicolumn{6}{|c|}{ Combatant population on January 1st (thousands) } \\
\hline Year & Table $1^{*}$ & Model 1 & Diff & Model 2 & Diff \\
\hline 1915 & 1,306 & 999 & 307 & 1,306 & 0 \\
\hline 1916 & 2,254 & 2,399 & -145 & 2,269 & -15 \\
\hline 1917 & 2,952 & 3,051 & -98 & 2,952 & 0 \\
\hline 1918 & 3,333 & 3,352 & -19 & 3,333 & 0 \\
\hline $1919^{* *}$ & 3,301 & 2,493 & 808 & 2,552 & 749 \\
\hline 1920 & $\mathrm{n} / \mathrm{a}$ & 1,013 & - & 1,076 & - \\
\hline 1921 & $\mathrm{n} / \mathrm{a}$ & 144 & - & 185 & - \\
\hline 1922 & $\mathrm{n} / \mathrm{a}$ & 73 & - & 81 & - \\
\hline \multicolumn{6}{|c|}{ Combatant deaths } \\
\hline Year & Table 1 & Model 1 & Diff & Model 2 & Diff \\
\hline 1914 & 30,626 & 30,527 & 99 & 30,591 & 35 \\
\hline 1915 & 77,132 & 77,115 & 17 & 77,107 & 25 \\
\hline 1916 & 139,519 & 139,202 & 317 & 139,591 & -72 \\
\hline 1917 & 188,293 & 187,544 & 749 & 188,322 & -29 \\
\hline 1918 & 186,025 & 185,208 & 817 & 186,041 & -16 \\
\hline \multicolumn{6}{|c|}{ Net Migration (thousands) } \\
\hline Year & Official & Model 1 & Diff & Model 2 & Diff \\
\hline 1914 & $\mathrm{n} / \mathrm{a}$ & 0 & - & 306 & - \\
\hline 1915 & $\mathrm{n} / \mathrm{a}$ & 0 & - & -442 & - \\
\hline 1916 & $\mathrm{n} / \mathrm{a}$ & 0 & - & 27 & - \\
\hline 1917 & $\mathrm{n} / \mathrm{a}$ & 0 & - & 77 & - \\
\hline 1918 & $\mathrm{n} / \mathrm{a}$ & 0 & - & 76 & - \\
\hline 1919 & $\mathrm{n} / \mathrm{a}$ & 1.2 & - & 1.3 & - \\
\hline 1920 & $\mathrm{n} / \mathrm{a}$ & 1.2 & - & 1.4 & - \\
\hline 1921 & $\mathrm{n} / \mathrm{a}$ & 1.4 & - & 1.4 & - \\
\hline
\end{tabular}

* Calculated as a weighted average from Table 1

** Official data given on 01.11.1918

A comparison with official data sources and Winter's estimates $(1976,2003)$ shows just one significant difference for 1919. The difference is explained by the fact that the data stemming from other sources refer to the end of the war (October 1 1918), whereas our estimates are calculated for January 1st, 1919 and include demobilization. Following 
Jdanov et al.: Estimates of mortality and population changes in England and Wales

the rules of migration minimization (see assumption (b) in the third section), the model with zero migration during the war years has been selected to reconstruct the mortality surface for England and Wales for the period around the First World War. For the further verification of Model 1, the age patterns of deaths and mortality have been compared to the corresponding estimates published by Winter $(1976,2003)$ (Figure 4). Although the estimated age-specific mortality curves look more smoothed, they show almost identical increases in mortality at ages 19-24 compared to the data on Prudential policy holders re-published by Winter (2003).

Figure 4: Distribution of deaths by age (top) and probabilities of death (bottom) for "total" population (sum of civilian and military) for 1913-1918, England and Wales, males. Left: Winter, J.M. (1976, 2003), original source: Burn, J. (1918). Right: Results of simulation
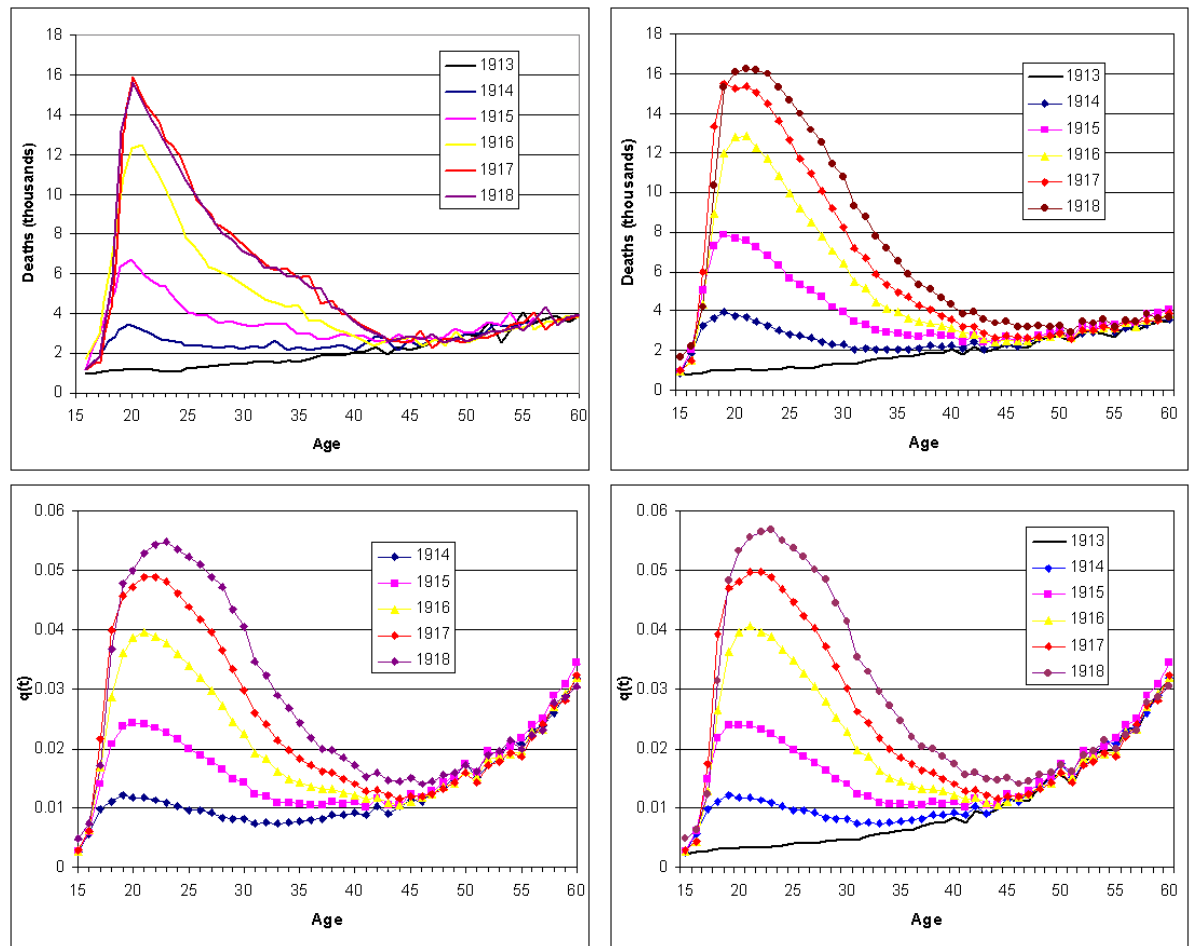
The reconstruction of the mortality surface for the total population of England and Wales enabled us to produce new continuous series of life tables for the years around the First World War. As expected, the effect of war loss is great. Compared to civilian males, the decrease in life expectancy at birth among the total of males was more rapid, showing a decline by 18 years between 1913 and 1918. Among the civilian males, the corresponding drop was about 10 years, suggesting that military casualties may have been included in part in the official statistics. The flu epidemic in 1918 is an additional factor that explains the peak in civilian deaths. As for females, the adjustments made have a negligible effect on the mortality trends for the period around the First World War.

Our results provide some insights into the age patterns of total population losses during the First World War. Figure 5 shows that the most striking excess male mortality in the total population has affected the ages 18-24, with the maximum peak being age at 23 in 1918. Between 1913 and 1918, the latter age shows a 15-16 fold increase in the probability of dying. At the same time, and according to the unadjusted official figures for the civilian population, males belonging to the same age interval experience only a three to four-fold jump in mortality risk. The inclusion of a combatant part of the population has a significant impact on the life expectancy indicators for the 1885-1899 cohorts (Figure 5). The maximum difference between adjusted and unadjusted series (based on the civilian population only) is almost four years in the 1896 cohort, i.e., for men aged 18 in 1914.

\section{Figure 5: Life expectancy at birth for the 1870-1910 cohorts, calculated from civilian and adjusted (total) data}

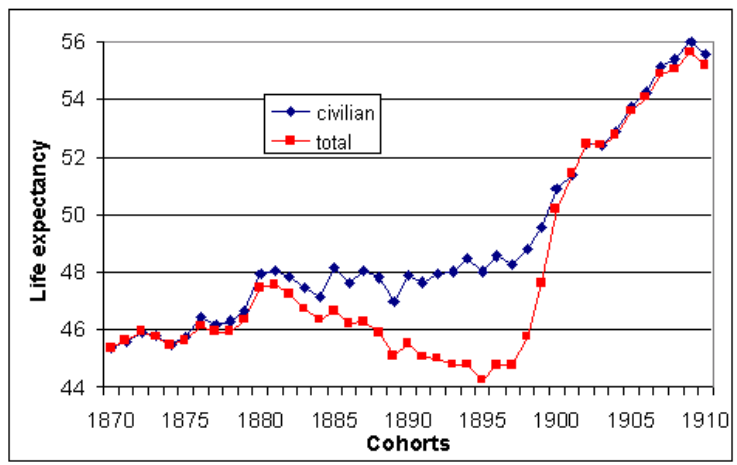

Although we have used rather fragmentary data for WWI, the reconstructed agespecific mortality surface of the total population of England and Wales is concordant with alternative estimates stemming from the Prudential life tables for 1915, 1916, and 1917 (published by Winter in 1976). 
Jdanov et al.: Estimates of mortality and population changes in England and Wales

\subsection{The Second World War}

Data on the military population during WW II are available at a much more detailed level (see Section 2 for more details). Thus, functional (15) requires only slight modifications to fit the additional data. The adjustment concerns the second term, which defines population size. As the data on the combatant population are available by five-year age groups and for each year of the war, we modify the model as follows:

$$
\begin{aligned}
& \quad \lambda_{1} \sum_{t_{\text {begin }}<t<t_{\text {end }}}\left(\mathbf{D}^{m}(t)^{-1}\left(\sum_{y} D^{m}(t, y)-\mathbf{D}^{a}(t)\right)\right)^{2}+ \\
& +\quad \lambda_{2} \sum_{t_{\text {begin }}<t<t_{\text {end }}}\left(\mathbf{P}^{m}(t)^{-1}\left(\sum_{y_{i}<y \leq y_{i+1}} P^{m}(t, y)-P^{m}\left(t, y_{i}: y_{i+1}\right)\right)\right)^{2}+ \\
& +\quad \lambda_{3} \sum_{t_{\text {begin }}<t<T}\left(\sum_{y} P^{c}(t, y)^{2}\right)^{-1} \sum_{y} M(t, y)^{2}+ \\
& +\quad \lambda_{4} \sum_{t_{\text {end }}<t<T} \mathbf{P}^{a}\left(t_{\text {begin }}+1\right)^{-2} \sum_{y}\left(t-t_{\text {end }}\right) P^{m}(t, y)^{2} \rightarrow \min _{b_{0}, \ldots, b_{n}, k_{0}, \ldots, k_{m}}
\end{aligned}
$$

where $P^{m}\left(t, y_{i}: y_{i+1}\right)$ is the population size for age group $\left[t-y_{i+1}, t-y_{i}\right]$ in $t$.

Similarly to WWI, we used as initial time point January 1st, 1939; the last time point was the date of the first postwar census (1951).

Overall, our results are very close to those yielded by the available official data on the total and military populations. For example, the estimated military deaths show no difference to the official statistics except for a negligible gap of around $0.15 \%$ (27 deaths) for 1941. The estimated and official population counts are also almost identical, with a maximum difference of less than $0.1 \%$ over all age groups and years.

The recalculated mortality surface of the total population of England and Wales for the Second World War demonstrates that mortality has a less significant effect, due to war operations, compared to our estimates for the First World War. Our data show that male life expectancy at birth decreased by about five years between 1939 and 1945 (compared to the corresponding drop of 16 years between 1914 and 1918), reaching the lowest level, 56 years, in 1945. At the same time, an inclusion of female military personnel hardly impacted the trends in life expectancy during the war years. Among the civilian population, a less significant drop in life expectancy at birth is visible only for 1939-1941 (Figure 6). The disruption in the mortality trends of the civilian population may be explained by the 
specific conditions of war. The number of civilian deaths owing to air strikes of the enemy was very close to the number of military deaths (in action) at the beginning of the war.

Figure 6: Probability of death at age 25 for the civilian and total population, England and Wales, males (left); life expectancy at age 0 for civilian and total population, England and Wales, males (right)
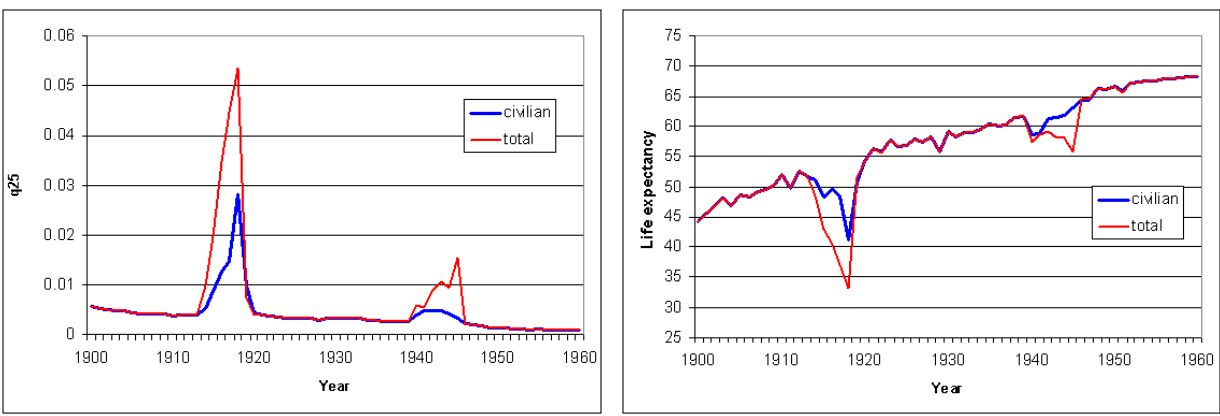

The reconstructed age-specific mortality patterns demonstrate that the growth of male mortality among the total population of England and Wales mostly concentrated on the ages 18-25 (as with the First World War), showing a five to seven-fold increases in mortality risk between 1938 and 1945 (Figure 7). The maximum level of mortality is held in 1945 by males aged 21, an age two years younger compared to 1918 .

The inclusion of the combatant population figures has a modest impact on the cohort mortality indicators. For example, the average life expectancy between ages 0 and 70 for the 1919 cohorts of the civilian and "total" population shows a maximum difference of 1.15 years (see Figure 8). Figures 6 and 8 confirm that the effect of WWII on mortality among the total population is less important than that of WWI. Unfortunately, it was not possible to validate our results on age-specific mortality patterns (as we did for the First World War).

\section{Conclusion}

We reconstructed a continuous series for war-time England and Wales, which includes estimates of the non-civilian population and deaths in war operations. We used the same model for both world wars. The adjusted data on England and Wales show significant effects of excess mortality among the military population on life expectancy trends in the total population during both wars.

We developed a mathematical model that allows for the reconstruction of mortality surfaces with the best possible fit of the available fragmentary data on different compo- 
Jdanov et al.: Estimates of mortality and population changes in England and Wales

Figure 7: Probability of death for the "total" population by age groups, 1938-1945, England and Wales, males. Results of simulation

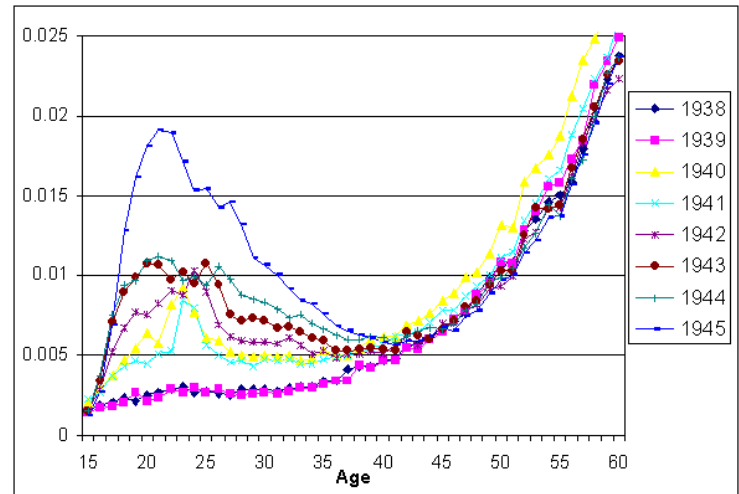

Figure 8: Male life expectancy within the range of ages 0 to 69 across cohorts born in 1900-1929 cohort: estimates from civilian only and adjusted (civilian+combatant) data

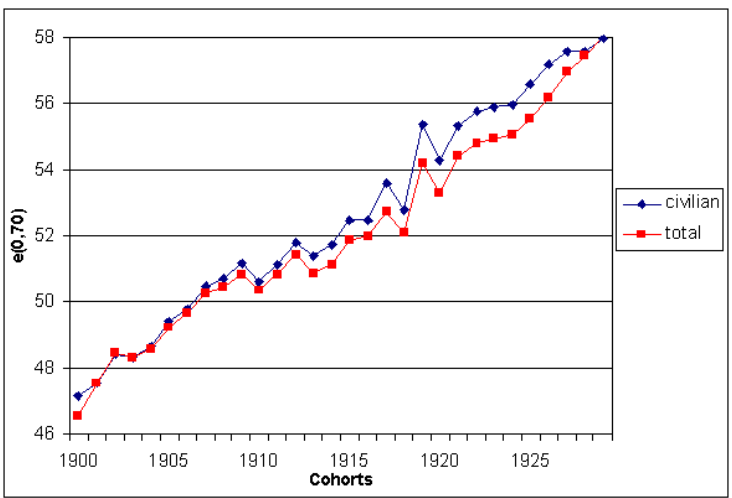


nents of the population movement. We showed that this modeling approach combined with a set of assumptions can be successfully applied to the estimation of mortality surfaces.

The modeling procedures applied in our study can be easily modified to become applicable under the conditions where even less data are available (the data for the censuses before and after the war being an exception, as they are complete). However, the reliability of the resulting estimates fully depends on the level of availability and quality of the data used for the modeling. We hope that the proposed method of mortality pattern reconstruction can be successfully applied to data on other countries that suffer from the exclusion of the military population from the statistics during the First and Second World War.

\section{Acknowledgements}

We are grateful to two anonymous reviewers for their very helpful comments on the manuscript. We also thank Susann Backer for most competent help with language editing. 
Jdanov et al.: Estimates of mortality and population changes in England and Wales

\section{References}

Brooke, E. (1972). The Emergency Medical Services. Medical Statistics. Casualties and Medical Statistics. History of the Second World War (United Kingdom Medical Series), Ed.: W.F. Mellor, HMSO, London, 635-825.

Burn, J. (1918). Industrial mortality 1915-1917. Journal of the Institute of Actuaries, 51, pp. 67-71.

Central Statistical Office (CSO). (1951, reprinted in 1995). Fighting with Figures. A Statistical Digest of the Second World War, Central Statistical Office, HMSO, London, $298 \mathrm{p}$.

Dudley, S. (1942). Discussion on Professor Greenwood's paper. Journal of the Royal Statistical Society, 105(1), pp. 12-13.

Ellis, F. (1972). The Royal Naval Medical Services. Medical Statistics. Casualties and Medical Statistics. History of the Second World War (United Kingdom Medical Series), Ed.: W.F. Mellor, HMSO, London, pp. 1-90.

HMSO. (1972). Casualties and Medical Statistics. History of the Second World War (United Kingdom Medical Series), Ed.: W.F. Mellor, HMSO, London, 893 p.

Mayne, H. (1972). The Army Medical Services. Medical Statistics. Casualties and Medical Statistics. History of the Second World War (United Kingdom Medical Series), Ed.: W.F. Mellor, HMSO, London, pp. 91-454.

Mitchell, T.J., Smith, G.M. (1931, reprinted in 1997). Casualties and medical statistics of the Great War, Army Medical Services, His Majesty's Stationery Office, London, $402 \mathrm{p}$.

The Army Council. (1921). General Annual Report of the British Army 1913-1919 (prepared by command of the Army Council). Parliamentary Paper 1921, XX, Cmd.1193.

The Army Service Forces, War Department. (1956). The Emergency Medical Services. Medical Statistics. Statistical Review. World War II, Downloaded from www.maxwell.af.mil/au/afhra/wwwroot/aafsd/aafsd_list_of_tables.html.

The Registrar Generals. (1951). Statistical Review of England and Wales for the Six Years 1940-1945., HMSO, London, II, pp. 10. 
The War Office. (1922). The Emergency Medical Services. Medical Statistics. Statistics of Military Effort of the British Empire during the Great War, 1914-1920, HMSO, London, 635-825.

Urlanis, B. (1971). Wars and Population, Progress Publishers, Moscow, 320 p.

Vallin, J. (1973). La mortalite par generation in France, depuis 1899., Paris: INED \& Presses Universitaries de France, 484 p.

Welch, S. (1972). The Royal Air Force Medical Services. Medical Statistics. Casualties and Medical Statistics. History of the Second World War (United Kingdom Medical Series), Ed.: W.F. Mellor, HMSO, London, pp. 455-633.

Winter, J. (1976). Some aspects of the demographic consequences of the First World War in Britain. Population Studies, 30(3), pp. 539-552.

Winter, J. (1977). Britain's "lost generation" of the First World War. Population Studies, 31(3), pp. 449-466.

Winter, J. (2003). The Great War and the British People, Palgrave Macmillan, 360 p. 
Jdanov et al.: Estimates of mortality and population changes in England and Wales 